\title{
MicroRNA-93-5p increases multidrug resistance in human colorectal carcinoma cells by downregulating cyclin dependent kinase inhibitor $1 \mathrm{~A}$ gene expression
}

\author{
SHI-JUN WANG ${ }^{1 *}$, YUN-FEI CAO $^{1 *}$, ZU-QING YANG $^{1}$, ZHI-YUAN JIANG $^{1}$, \\ BIN CAI $^{1}$, JIAO GUO ${ }^{2}$, SEN ZHANG ${ }^{1}$, XIAO-LONG ZHANG ${ }^{1}$ and FENG GAO ${ }^{1}$ \\ ${ }^{1}$ Department of Colorectal and Anal Surgery, First Affiliated Hospital of Guangxi Medical University; \\ ${ }^{2}$ Experimental Department, Affiliated Tumor Hospital of Guangxi Medical University, Nanning, Guangxi 530021, P.R. China
}

Received August 8, 2015; Accepted September 30, 2016

DOI: $10.3892 / \mathrm{ol} .2016 .5463$

\begin{abstract}
Multidrug resistance (MDR) impedes successful chemotherapy in colorectal carcinoma (CRC) and emerging evidence suggests that microRNAs (miRs) are involved in the development of MDR. In the present study, the role of miR-93-5p in the modulation of drug resistance in CRC was investigated using HCT-8 and MDR HCT-8/vincristine (VCR) cell lines. The results demonstrated upregulated expression of miR-93-5p and MDR protein 1 (MDR1) in HCT-8/VCR cells, compared with the parental HCT-8 cells. Furthermore, cyclin-dependent kinase inhibitor $1 \mathrm{~A}$ (CDKN1A) was identified as a potential target of miR-93-5p using miR target analysis tools, including PicTar, TargetScan and miRanda. In addition, inhibition of miR-93-5p expression in HCT-8/VCR cells markedly downregulated MDR1 gene expression, upregulated CDKN1A gene expression and induced cell cycle arrest in $\mathrm{G}_{1}$. Conversely, the overexpression of miR-93-5p in HCT-8/VCR cells upregulated MDR1 gene expression, downregulated CDKN1A gene expression and promoted $\mathrm{G}_{1} / \mathrm{S}$ transition. Furthermore, the in vitro drug sensitivity assay performed suggested that downregulation of miR-93-5p enhanced the sensitivity of HCT-8/VCR cells to VCR, while the upregulation of miR-93-5p decreased the sensitivity of HCT-8 cells to VCR. In conclusion, the results of the present study suggest that miR-93-5p serves a role in the development of MDR through downregulating CDKN1A gene expression in CRC.
\end{abstract}

Correspondence to: Professor Feng Gao, Department of Colorectal and Anal Surgery, First Affiliated Hospital of Guangxi Medical University, 6 Shuangyong Road, Nanning, Guangxi 530021, P.R. China

E-mail: gaofeng0771@163.com

*Contributed equally

Key words: colorectal carcinoma, multidrug resistance, microRNA-93, multidrug resistance protein 1 , cyclin dependent kinase inhibitor $1 \mathrm{~A}$

\section{Introduction}

Colorectal carcinoma (CRC) is the third most frequent malignant cancer worldwide (1) and has rapidly increased in incidence in recent years (2). In the United States of America, $\mathrm{CRC}$ is the leading cause of cancer-associated morbidity and mortality (3). In China, CRC ranks as the fourth most frequently occurring cancer and the fifth leading cause of cancer-associated mortality (4). Chemotherapy is important in the comprehensive treatment of CRC, and remains the primary treatment for resectable and advanced CRC (5). However, certain patients with CRC who are treated with chemotherapeutics exhibit a poor initial response or gradually develop resistance, a phenomenon known as multidrug resistance (MDR) $(6,7)$. The emergence of MDR is an obstacle to the successful treatment of CRC, leading to poor prognosis, relapse and metastasis of the tumor (8). The underlying molecular mechanisms of chemoresistance are complex and multifactorial, and remain to be completely elucidated. Multiple processes participate in the development of MDR, including those involved in drug transport and metabolism, DNA damage repair and apoptotic regulation $(9,10)$.

Evidence increasingly suggests that microRNAs (miRs) serve an essential role in MDR (11-14). miRs are evolutionarily conserved, small non-coding single-stranded RNA molecules of between 19 and 24 nucleotides in length $(15,16)$. The primary function of miRs is to negatively regulate gene expression at the post-transcriptional level, through binding to the $3^{\prime}$ untranslated region of their target mRNA, in part or in full, and subsequently mediating its degradation or inhibiting its translation $(17,18)$. miRs are involved in a number of biological processes, including metabolism, differentiation, proliferation, cell-cycle control and apoptosis (18-20). Furthermore, increasing research indicates that miRs function as oncogenes and tumor suppressors, and that the dysregulation of miRs is associated with the development of MDR in various types of cancer (21-23). For example, miR-17-5p was demonstrated to be upregulated in chemoresistant CRC cells, which promoted cell invasiveness (24). In addition, miR-508-5p was observed to be downregulated in drug-resistant gastric cancer cells, where its overexpression was demonstrated to reverse drug 
resistance (25). Various miRs are known to be involved in the regulation of MDR in cancer, including miR-625-3p, miR-1915, miR-200c and miR-203 (26-29).

miR-93 belongs to the miR-106b-25 cluster and is located at the human chromosome locus 7q22.1 (30). miR-93 appears to be frequently dysregulated in various types of human cancer, including gastric, ovarian, breast and, in particular, CRC (31-35). Furthermore, miR-93 has been demonstrated to participate in the development of MDR in ovarian cancer cells and prolactinomas $(36,37)$. Zhou et al (33) reported that the expression levels of miR-93 were regulated by chemotherapeutics in human colon cancer cells and, thus, may be associated with treatment-resistance in colon cancer. However, to the best of our knowledge, the exact role of miR-93 in the development of MDR in CRC has not yet been investigated and verified. Therefore, in the present study, the role of miR-93-5p in the modulation of drug-resistance in human CRC was examined using HCT-8 and multidrug-resistant HCT-8/vincristine (VCR) cell lines. The results of the current study suggest that miR-93-5p overexpression in CRC serves an essential role in the development of MDR, via miR-93-5p negatively regulating the expression of its target gene, cyclin-dependent kinase inhibitor 1A (CDKN1A).

\section{Materials and methods}

Cell lines and cultures. The HCT-8 human ileocecal colorectal adenocarcinoma cell line was obtained from the Kunming Cell Bank of the Chinese Academy of Sciences (Kunming, China), while the HCT-8/VCR multidrug-resistant variant was purchased from the Modern Analysis and Testing Center of Central South University (Changsha, China). Cells were maintained in RPMI-1640 medium (Gibco; Thermo Fisher Scientific, Inc., Waltham, MA, USA), supplemented with $10 \%$ fetal bovine serum (Gibco; Thermo Fisher Scientific, Inc.) at $37^{\circ} \mathrm{C}$ in a humidified atmosphere containing $5 \% \mathrm{CO}_{2}$. A total of $1 \mu \mathrm{g} / \mathrm{ml} \mathrm{VCR}$ was added to HCT-8/VCR cell cultures to maintain their MDR phenotype.

Reverse transcription-quantitative polymerase chain reaction (RT-qPCR) of miR-93-5p. Total RNA (40 ng) was extracted from the cultured cells using TRIzol ${ }^{\circledR}$ reagent (Invitrogen; Thermo Fisher Scientific, Inc.). Polyadenylation was subsequently carried out, in which first strand cDNA synthesis was performed using the miRcute miRNA First-strand cDNA Synthesis kit (Tiangen Biotech Co., Ltd., Beijing, China), according to the manufacturer's protocol. The miRcute miRNA qPCR Detection kit (Tiangen Biotech Co., Ltd.) was used for the following RT-qPCR analysis. Briefly, the $20 \mu \mathrm{l}$ PCR reaction volume included $10 \mu \mathrm{l} 2 \mathrm{X}$ miRcute miRNA Premix, $2 \mu \mathrm{l}$ first strand cDNA, $7.2 \mu \mathrm{l}$ RNase-free $\mathrm{ddH}_{2} \mathrm{O}, 0.4 \mu \mathrm{l}$ forward primer (final concentration $200 \mathrm{nM}$ ) and $0.4 \mu \mathrm{l}$ reverse primer (final concentration $200 \mathrm{nM}$ ). The reactions were incubated in a 96 -well optical plate at $94^{\circ} \mathrm{C}$ for $2 \mathrm{~min}$, followed by 40 cycles at $94^{\circ} \mathrm{C}$ for $20 \mathrm{sec}$ and $60^{\circ} \mathrm{C}$ for $34 \mathrm{sec}$. The universally expressed U6 small nuclear RNA (snRNA) was used as an internal control for normalization. Primers for miR-93-5p (cat. no. CD201-0041) and U6 (cat. no., CD201-0145) were acquired from Tiangen Biotech Co., Ltd. The $2^{-\Delta \Delta \mathrm{Cq}}$ method (38) was used to calculate the relative expression levels of miR-93-5p for each cell line. The treated group included HVT-8 cells, whereas the control group was HCT-8/VCR cells. $\Delta \mathrm{Cq}$ was calculated as follows: Average miR-93-5p Cq-average U6 snRNA Cq. $\triangle \Delta \mathrm{Cq}$ was calculated as the following: $\Delta \mathrm{Cq}$ of the treated group $-\Delta \mathrm{Cq}$ of the control group. The results are presented as the fold change in expression in HCT- 8 cells relative to HCT-8/VCR cells.

miR transfection. The miR-93-5p mimic (cat. no. B01001) and inhibitor (cat. no. B03001), and the corresponding negative control (NC; cat. no. B04001), were designed and chemically synthesized by GenePharma Co., Ltd. (Shanghai, China). HCT-8/VCR and HCT-8 cells were seeded into 6-well plates at a density of $2 \times 10^{5}$ cells/well and cultured at $37^{\circ} \mathrm{C}$ for $24 \mathrm{~h}$. A total of 100 pmol miR-93-5p mimic, miR-93-5p inhibitor or NC was transfected into target cells using $5 \mu$ Lipofectamine ${ }^{\circledR} 2000$ (Thermo Fisher Scientific, Inc.) and Opti-MEM ${ }^{\circledR}$ I reduced serum medium (Invitrogen; Thermo Fisher Scientific, Inc.), according to the manufacturer's protocol.

Bioinformatics method. The following online miRNA target prediction algorithms were used to evaluate the potential target genes of miR-93-5p: PicTar (http://www.pictar.org/), TargetScan (http://www.targetscan.org/vert_71/) and miRanda (http://www.microrna.org/microrna/home.do).

$R T$-qPCR of MDR protein 1 (MDRl) and CDKN1A. Total RNA (500 ng) was isolated from the cells using TRIzol ${ }^{\circledR}$ reagent, according to the manufacturer's protocol. cDNA was synthesized using a PrimeScript ${ }^{\mathrm{TM}}$ RT reagent kit (cat. no., RR037A; Takara Biotechnology Co., Ltd., Dalian, China). The PCR reaction mix contained 12.5 $\mu$ l FastStart Universal SYBR Green Master (Roche Diagnostics GmbH, Mannheim, Germany), $0.25 \mu \mathrm{l}$ forward and reverse primers (final concentration, $300 \mathrm{nM}$ ) and $2.5 \mu \mathrm{l}$ cDNA, made up to a final volume of $25 \mu \mathrm{l}$ with RNase-free $\mathrm{ddH}_{2} \mathrm{O}$. Primers for MDR1, CDKN1A and GAPDH were acquired from GenePharma Co. Ltd. MDR1 (GeneBank accession number, NM_000927.4): 5'-GTTGCTGCTTACATTCAGGTTTC-3' (sense) and 5'-ACCAGCCTATCTCCTGTCGC-3' (antisense); CDKN1A (GeneBank accession number, NM_000389.4): 5'-CCTTCCTCATCCACCCCATC-3' (sense) and 5'-CCCTGT CCATAGCCTCTACTGC-3' (antisense); GAPDH (GeneBank accession number, NM_001256799.2): 5'-GTCAGCCGCATC TTCTTT-3' (sense) and 5'-CGCCCAATACGACCAAAT-3' (antisense). The ABI 7500 real time PCR system with 7500 software version 2.0.6 (Applied Biosystems; Thermo Fisher Scientific, Inc.) was utilized to quantify the expression levels of RNA. The thermocycling conditions for the RT-qPCR were as follows: $50^{\circ} \mathrm{C}$ for $2 \mathrm{~min}, 95^{\circ} \mathrm{C}$ for $10 \mathrm{~min}$ and 40 cycles of $95^{\circ} \mathrm{C}$ for $15 \mathrm{sec}$ and $60^{\circ} \mathrm{C}$ for $1 \mathrm{~min}$. The expression levels of MDR1, CDKN1A and GAPDH were assessed using the $2^{-\Delta \Delta C q}$ method, as aforementioned, while GAPDH was used as an internal control.

Western blot analysis. At $48 \mathrm{~h}$ following transfection, the cells were washed with $1 \mathrm{X}$ PBS and then lysed using radioimmunoprecipitation assay buffer (Beyotime Institute of Biotechnology, Shanghai, China) for $30 \mathrm{~min}$ at $4^{\circ} \mathrm{C}$. The protein concentration was measured using a bicinchoninic 
acid protein assay kit (Beijing Solarbio Science \& Technology Co., Ltd., Beijing, China), following the manufacturer's protocol, and $30 \mu \mathrm{g}$ protein was separated by $10 \%$ SDS-PAGE for western blot analysis. Once the proteins were transferred to a polyvinylidene difluoride membrane (Merck Millipore, Darmstadt, Germany), the membrane was incubated in bovine serum albumin blocking buffer (Beijing Solarbio Science \& Technology Co., Ltd.) at room temperature for $1 \mathrm{~h}$ and washed with Tris-buffered saline and Tween-20 (TBST; Beijing Solarbio Science \& Technology Co., Ltd.) three times (5 min/time). Monoclonal antibodies specific to MDR1 (cat. no. 13342; dilution, 1:1,000), CDKN1A (cat. no. 2947; dilution, 1:1,000) or $\beta$-actin (cat. no. 12620; dilution, 1:1,000; Cell Signaling Technology, Inc., Danvers, MA, USA) were utilized and the membranes were incubated overnight at $4^{\circ} \mathrm{C}$. $\beta$-actin was used as the internal control. Following washing three times with TBST (5 min/time), the membrane was probed with horseradish peroxidase-conjugated goat anti-rabbit immunoglobulin G (cat. no. KC-RB-035; dilution, 1:5,000; KangChen Bio-tech, Shanghai, China) for $1 \mathrm{~h}$ at room temperature. Subsequently, the membranes were washed with TBST three times (5 min/time), ECL Plus Western Blotting Substrate (Pierce; Thermo Fisher Scientific, Inc.) was used to identify protein bands and ImageJ software (National Institutes of Health, Bethesda, MD, USA; version 1.48) was used to quantify their intensity.

Rhodamine 123 (Rh-123) was used to measure MDRl efflux. $\mathrm{Rh}-123$ is a fluorescent dye (Dojindo Molecular Technologies, Inc., Rockville, MD, USA) that binds to MDR1, which is an established tool to examine the transport activity of MDR1 (39). A total of $5 \times 10^{5}$ cells were incubated with $20 \mu \mathrm{M}$ $\mathrm{Rh}-123$ for $1 \mathrm{~h}$ at $37^{\circ} \mathrm{C}$. Following incubation, cells were washed three times with PBS to remove free Rh-123 from the medium. Cells were subsequently kept in Rh-123-free medium at $37^{\circ} \mathrm{C}$. The intracellular fluorescence intensity of the remaining Rh-123 was examined using fluorescence-activated cell sorting with a flow cytometer (FC500; Beckman Coulter, Inc., Brea, CA, USA).

In vitro drug sensitivity assay. A total of $24 \mathrm{~h}$ following miR transfection, the cells were seeded into 96-well plates at a density of $3 \times 10^{3}$ cells/well. Following cellular adhesion, VCR was added to provide the following final concentrations: 0.001 , $0.01,0.1,1,10$ and 100 times the peak human plasma concentration. The peak serum concentration of VCR was taken to be $0.5 \mu \mathrm{g} / \mathrm{ml}$, as previously determined by Zhu et al (40). The Cell Counting kit-8 (CCK-8; Dojindo Molecular Technologies, Inc., Rockville, MD, USA) assay was performed to assess cell viability at $72 \mathrm{~h}$ following miR transfection. The absorbance of each well at $450 \mathrm{~nm}$ was detected using the ELx $808^{\mathrm{TM}}$ Absorbance Reader with Gen5 software version 2.00.20 (BioTek Instruments, Inc., Winooski, VT, USA). Furthermore, the half-maximal inhibitory concentration $\left(\mathrm{IC}_{50}\right)$ of VCR on cell viability was determined by calculating the dose-response curve.

Cell cycle assay. A total of $72 \mathrm{~h}$ following miR transfection, HCT-8/VCR cells were harvested by centrifugation at $300 \mathrm{xg}$ for $10 \mathrm{~min}$ at room temperature. Cells were washed three times with cold PBS and fixed in ice-cold $75 \%$ ethanol at $4^{\circ} \mathrm{C}$ overnight. Fixed cells were subsequently rehydrated in $200 \mu \mathrm{l}$ ice-cold PBS and treated with $20 \mu 1$ RNase (Yeasen Biotech Co., Ltd., Shanghai, China) for $30 \mathrm{~min}$. Subsequently, the cell samples were treated with $400 \mu \mathrm{l}$ propidium iodide staining solution, followed by incubation at $4^{\circ} \mathrm{C}$ for $30 \mathrm{~min}$ in the dark. The cell cycle distribution for each sample was estimated using FlowJo software (version 7.6.1; FlowJo, LLC, Ashland, OR, USA), according to the manufacturer's protocol.

Statistical analysis. The data are presented as the mean \pm standard deviation of triplicate results. The difference between means was statistically analyzed using a two-tailed Student's $t$-test when 2 groups were compared, or one-way analysis of variance (ANOVA) when $>2$ groups were compared. In ANOVA, post hoc tests were used for multiple comparisons as follows: The Fisher's least significant difference and Students-Newman-Keuls methods were applied if equal variances were assumed; the Games-Howell method was applied if equal variances were not assumed. All statistical analyses were performed using SPSS software (version 17.0; SPSS, Inc., Chicago, IL, USA). P $<0.05$ was considered to indicate a statistically significant difference.

\section{Results}

Expression of miR-93-5p and MDRI in HCT-8 and HCT-8/VCR CRC cells. miR-93-5p and MDR1 mRNA expression levels were examined in HCT-8 and HCT-8/VCR cell lines using RT-qPCR, and MDR1 protein levels were evaluated using western blotting. The results of the present study demonstrated that the relative expression of miR-93-5p was significantly increased in HCT-8/VCR cells, compared with HCT-8 cells $(\mathrm{P}<0.001$; Fig. 1A). In addition, the relative expression levels of MDR1 mRNA were significantly increased in HCT-8/VCR cells, compared with the parental HCT- 8 cells $(\mathrm{P}=0.001$; Fig. 1B). Similarly, MDR1 protein levels were increased in HCT-8/VCR cell lines, compared with HCT-8 cell lines $(\mathrm{P}=0.011$; Fig. $1 \mathrm{C}$ and $\mathrm{D})$.

miR-93-5p regulates the expression of MDR1. To investigate whether miR-93-5p is involved in the regulation of MDR1 gene expression, HCT-8/VCR cells were transfected with the miR-93-5p mimic, miR-93-5p inhibitor or the NC. MDR1 mRNA and protein expression levels were evaluated using RT-qPCR and western blotting, respectively. The results indicated that MDR1 mRNA $(\mathrm{P}<0.001$; Fig. $2 \mathrm{~A})$ and protein $(\mathrm{P}<0.001$; Fig. 2B and $\mathrm{C})$ expression levels were significantly decreased in HCT-8/VCR cells transfected with the miR-93-5p inhibitor, compared with the NC-transfected cells. Conversely, MDR1 mRNA $(\mathrm{P}<0.001$; Fig. 2A) and protein $(\mathrm{P}<0.001$; Fig. 2B and C) expression levels were significantly increased in HCT-8/VCR cells transfected with the miR-93-5p mimic, compared with the NC-transfected cells.

Dysregulation of miR-93-5p is associated with the transport activity of MDR1. In order to verify the role of miR-93-5p in the regulation of MDR1 expression, MDR1 transport activity was assessed by measuring the intracellular accumulation of Rh-123, whereby increased MDR1 transport activity is indicated by decreased intracellular Rh-123 fluorescence. As 
A

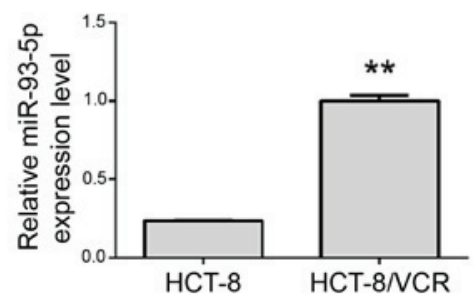

$\mathrm{C}$

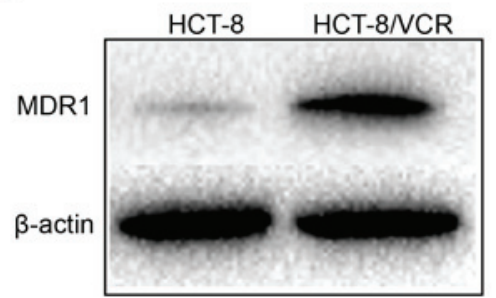

B

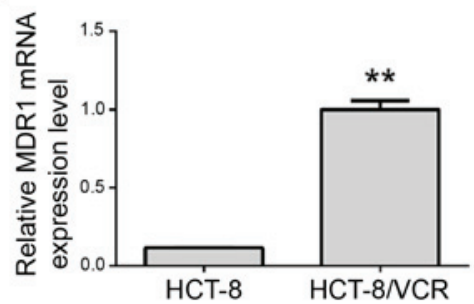

$\mathrm{D}$

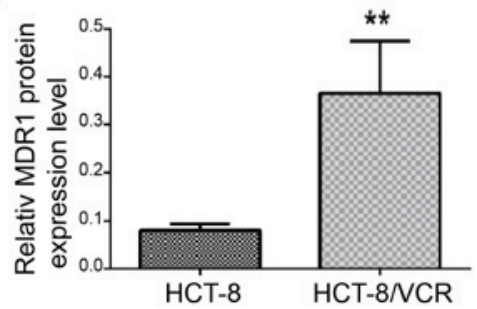

Figure 1. (A) Relative expression levels of miR-93-5p in HCT-8 and HCT-8/VCR cells, detected using RT-qPCR. Relative expression of miR-93-5p was normalized to U6 small nuclear RNA. (B) Relative expression levels of MDR1 mRNA in HCT-8 and HCT-8/VCR cells, as measured using RT-qPCR. GAPDH was used as an internal loading control. Values are presented as the mean \pm standard deviation from three independent experiments. ${ }^{* *} \mathrm{P}<0.01 \mathrm{vs}$. HCT- 8 cells. (C) MDR1 protein levels were measured using western blot analysis. $\beta$-actin was used as an internal loading control. (D) MDR1 protein expression was quantified through image analysis. Values are presented as the mean \pm standard deviation from three independent experiments. miR, microRNA; RT-qPCR, reverse transcription-quantitative polymerase chain reaction; MDR1, multidrug resistance protein 1; VCR, vincristine.

A

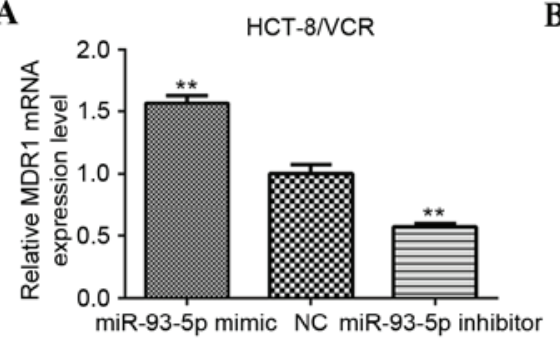

B

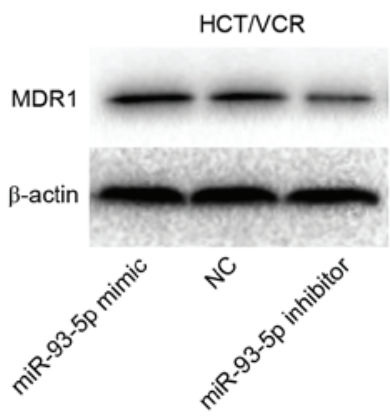

C

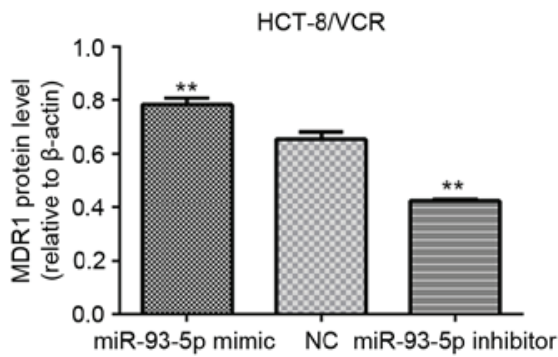

Figure 2. (A) Relative expression levels of MDR1 mRNA in HCT-8/VCR cells transfected with miR-93-5p mimic, miR-93-5p inhibitor or a NC were measured using the reverse transcription-quantitative polymerase chain reaction $48 \mathrm{~h}$ following the transfection. GAPDH was used as an internal loading control (B) MDR1 protein levels in HCT-8/VCR cells transfected with miR-93-5p mimic, miR-93-5p inhibitor or a NC were analyzed using western blot analysis at $72 \mathrm{~h}$ following transfection. $\beta$-actin was used as an internal loading control. (C) MDR1 protein expression was quantified through image analysis. Values are presented as the mean \pm standard deviation from three independent experiments. ${ }^{* *} \mathrm{P}<0.01$ vs. the NC group. miR, microRNA; MDR1, multidrug resistance protein 1; NC, negative control; VCR, vincristine.

presented in Fig. 3A and B, the fluorescence intensity of Rh-123 was significantly increased in HCT-8/VCR cells transfected with the miR-93-5p inhibitor, compared with cells transfected with the NC $(\mathrm{P}<0.001)$. Conversely, HCT-8/VCR cells transfected with the miR-93-5p mimic exhibited significantly decreased Rh-123 fluorescence intensity, compared with the cells transfected with the $\mathrm{NC}(\mathrm{P}=0.034$; Fig. $3 \mathrm{~A}$ and $\mathrm{B})$. These results were consistent with those of the RT-qPCR and western blot analyses.

miR-93-5p modulates the sensitivity of human CRC cells to anti-cancer drugs. To determine whether miR-93-5p is directly involved in the development of drug resistance in human CRC cells, the sensitivity of miR-93-5p mimic-transfected HCT-8 and miR-93-5p inhibitor-transfected HCT-8/VCR cells to increasing concentrations of VCR was examined using a
CCK-8 assay. miR-93-5p inhibitor-transfected HCT-8/VCR cells exhibited enhanced sensitivity to VCR $\left(\mathrm{IC}_{50}, 4.472 \mu \mathrm{M}\right)$, compared with the NC-transfected cells $\left(\mathrm{IC}_{50}, 100.7 \mu \mathrm{M}\right.$; Fig. 3C). Conversely, the sensitivity of miR-93-5p mimic-transfected HCT-8 cells to VCR $\left(\mathrm{IC}_{50}, 11.37 \mu \mathrm{M}\right)$ was decreased, compared with the NC-transfected cells $\left(\mathrm{IC}_{50}, 0.8884\right.$ $\mu \mathrm{M}$; Fig. 3C). The results of the present study indicate that miR-93-5p has an important role in the regulation of MDR phenotypes in human CRC cells.

$C D K N 1 A$ as a target of miR-93-5p repression. CDKN1A, also known as p21 ${ }^{\text {Cip } 1}$, is a key member of the Cip/Kip family of cyclin kinase inhibitors and acts as a regulator of cell cycle progression in $\mathrm{G}_{1}(41,42)$. CDKN1A was identified as a potential target of miR-93-5p using the miR target analysis tools PicTar, TargetScan and miRanda $(43,44)$. In order to evaluate 
$\mathbf{A}$

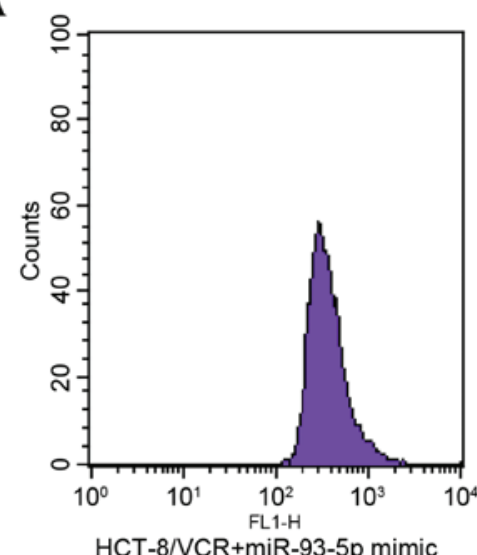

B

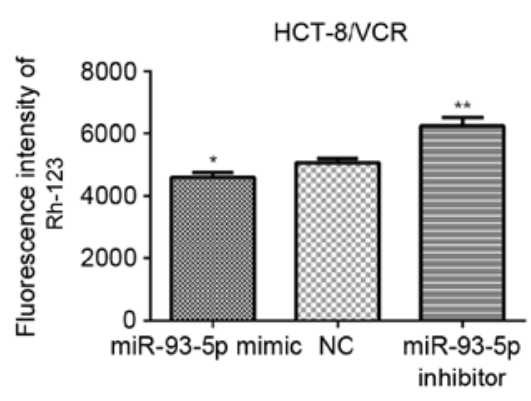

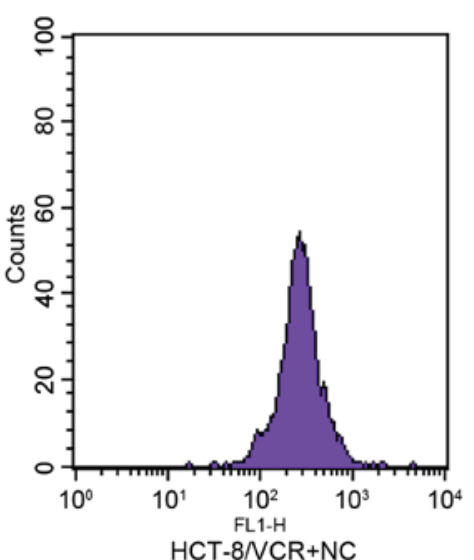

C

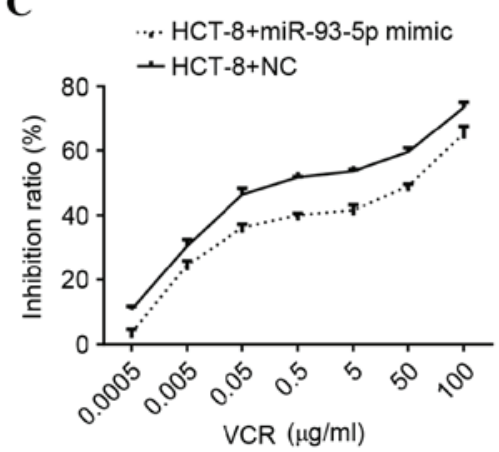

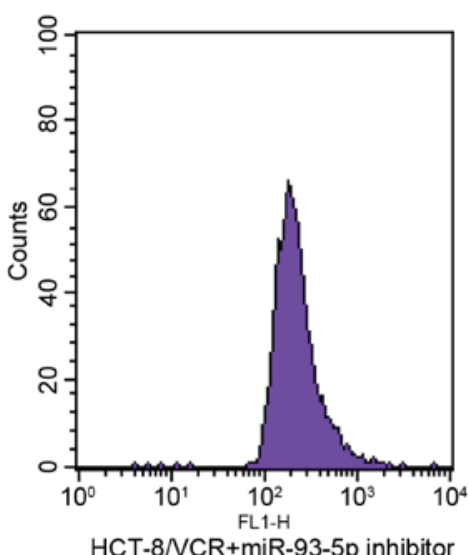

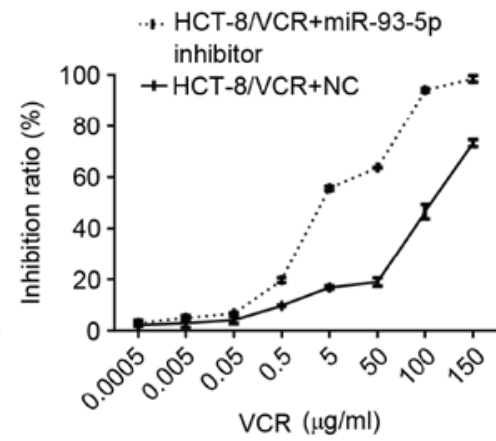

Figure 3. miR-93-5p promotes efflux of Rh-123 in HCT-8/VCR cells. (A) The release index of Rh-123 in HCT-8/VCR cells transfected with miR-93-5p mimic, miR-93-5p inhibitor or a NC was determined following $1 \mathrm{~h}$ incubation with $20 \mu \mathrm{M} \mathrm{Rh}-123$. The fluorescence intensity of Rh-123 in cells was measured using fluorescence activated cell sorting. (B) Quantification of Rh-123 fluorescence intensity. Values are presented as the mean \pm standard deviation from three independent experiments. "P $<0.05$; ${ }^{* *} \mathrm{P}<0.01$ vs. the NC group. (C) A total of $24 \mathrm{~h}$ following transfection of HCT-8 and HCT-8/VCR cells with miR-93-5p mimic, miR-93-5p inhibitor or a NC, cells were treated with increasing concentrations of VCR for $72 \mathrm{~h}$. Inhibition of cell viability was subsequently measured using the Cell Counting kit-8 assay. miR, microRNA; Rh-123, rhodamine 123; NC, negative control; MDR1, multidrug resistance protein 1; VCR, vincristine; FL1-H, fluorescence 1 height.

A

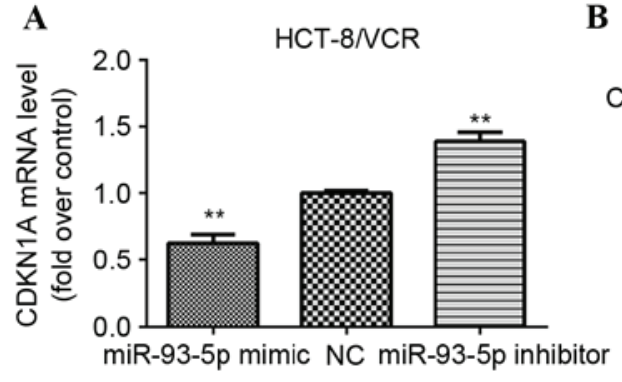

B

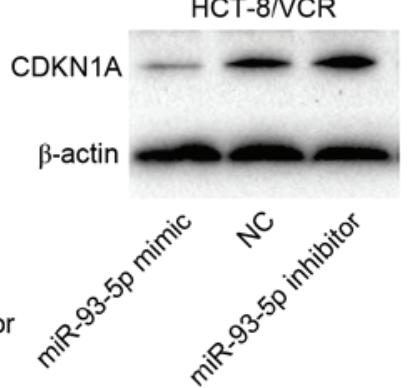

C

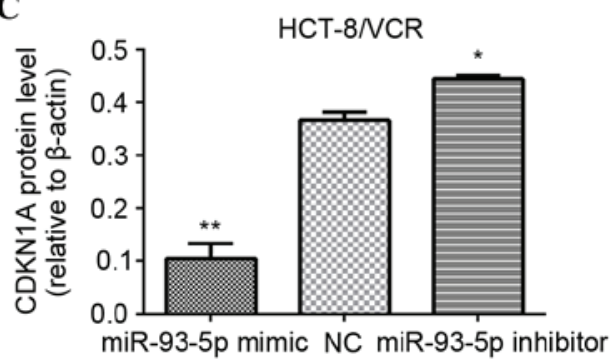

Figure 4. (A) Relative expression levels of CDKN1A mRNA in HCT-8/VCR cells transfected with miR-93-5p mimic, miR-93-5p inhibitor or an NC were determined using the reverse transcription-quantitative polymerase chain reaction $48 \mathrm{~h}$ following transfection. GAPDH was used as an internal loading control. (B) CDKN1A protein levels in HCT-8/VCR cells transfected with miR-93-5p mimic, miR-93-5p inhibitor or an NC were analyzed using western blotting $72 \mathrm{~h}$ following transfection. $\beta$-actin was used as an internal control. (C) Relative expression of CDKN1A protein was quantified through image analysis. Values are presented as the mean \pm standard deviation from three independent experiments. ${ }^{*} \mathrm{P}<0.05 ;{ }^{* *} \mathrm{P}<0.01$ vs. the NC group. miR, microRNA; CDKN1A, cyclin-dependent kinase inhibitor 1A; NC, negative control; VCR, vincristine.

whether miR-93-5p modulates MDR through the downregulation of CDKN1A gene expression in human CRC cells, HCT-8/VCR cells were transfected with a miR-93-5p mimic, miR-93-5p inhibitor or an NC. A total of $72 \mathrm{~h}$ following transfection, RT-qPCR and western blot analyses were performed to evaluate the expression levels of CDKN1A mRNA and protein, respectively. Significant upregulation of CDKN1A
mRNA expression levels was observed in the miR-93-5p inhibitor-transfected cells $(\mathrm{P}<0.001)$, and significant downregulation of CDKN1A mRNA expression levels was observed in the miR-93-5p mimic-transfected cells $(\mathrm{P}<0.0001)$, compared with NC-transfected cells (Fig. 4A). Furthermore, as presented in Fig. 4B and $C$, transfection with the miR-93-5p mimic significantly reduced HCT-8/VCR cell CDKN1A protein 
A
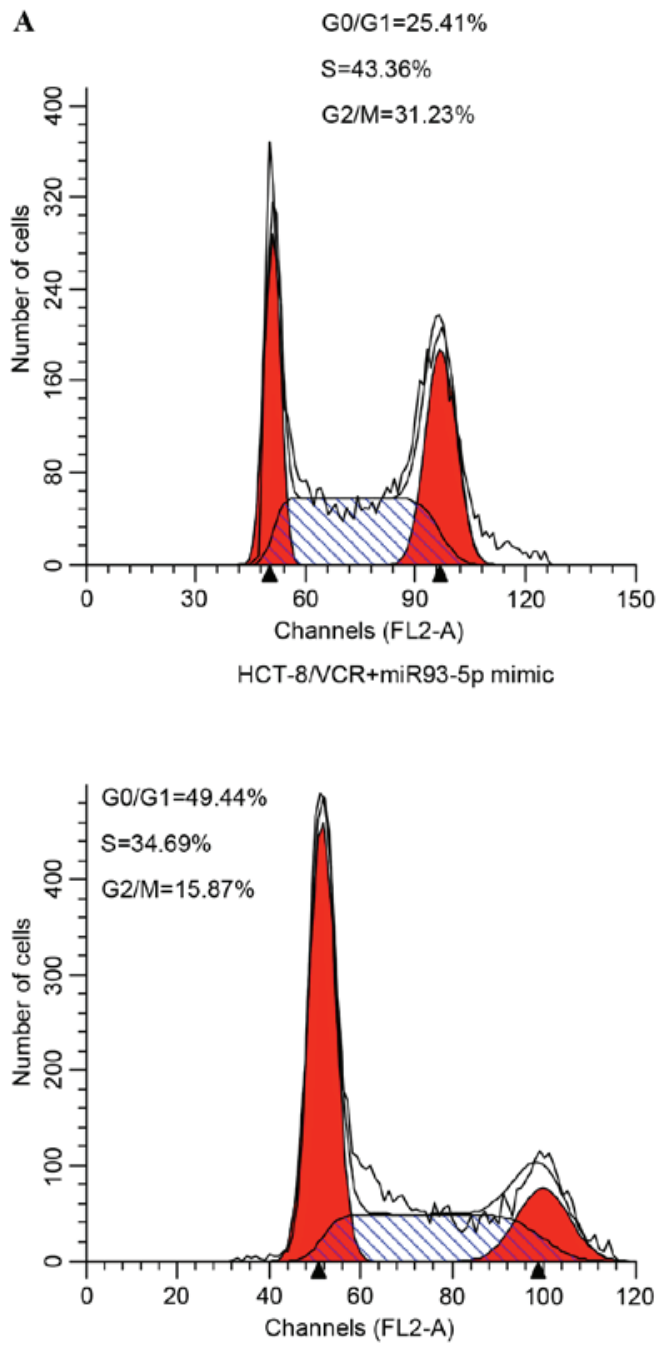

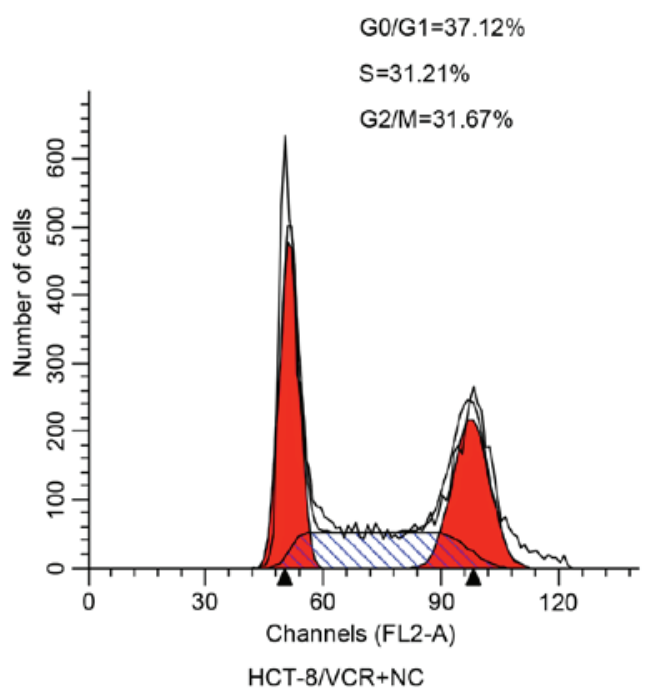

B

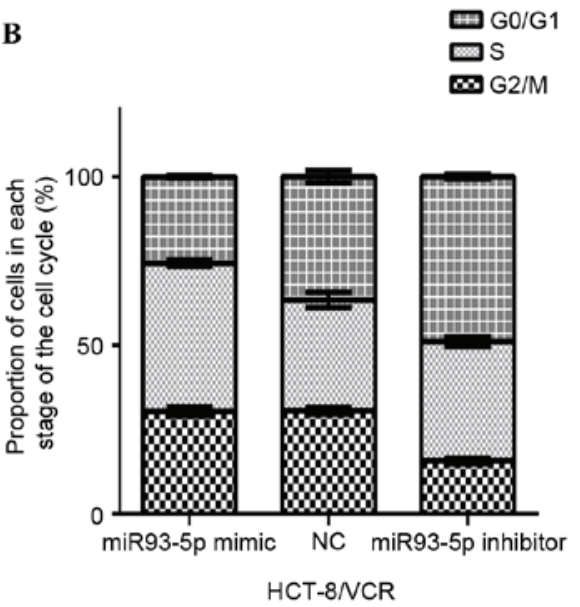

HCT-8NCR+miR93-5p inhibitor

Figure 5. (A) Cell cycle distribution of HCT-8/VCR cells transfected with miR-93-5p mimic, miR-93-5p inhibitor or an NC was analyzed $72 \mathrm{~h}$ following transfection using flow cytometry. Overexpression of miR-93-5p induced cell cycle progression in HCT-8/VCR cells. (B) Histogram showing the percentage of cells in $\mathrm{G}_{0} / \mathrm{G}_{1}, \mathrm{~S}$ and $\mathrm{G}_{2} / \mathrm{M}$ cell cycle phases. Values are presented as the mean \pm standard deviation from three independent experiments. miR, microRNA; NC, negative control; FL2-A, FL2-area; VCR, vincristine.

expression levels $(\mathrm{P}<0.001)$, while transfection with the miR-93-5p inhibitor significantly increased CDKN1A protein expression levels $(\mathrm{P}<0.001)$, compared with transfection of the NC siRNA.

Inhibition of miR-93-5p induces $G_{1}$ cell cycle arrest in $H C T-8 /$ VCR cells. A total of $72 \mathrm{~h}$ following transfection with the miR-93-5p mimic or inhibitor, the cell cycle distribution of HCT-8/VCR cells was analyzed using flow cytometry. As presented in Fig. 5A, the percentage of cells in $\mathrm{G}_{1}$ was significantly increased in the inhibitor-treated group, compared with the NC group $(48.94 \pm 0.64 \%$ vs. $36.57 \pm 1.81 \%$; $\mathrm{P}<0.001)$. Conversely, the percentage of cells in $\mathrm{G}_{2} / \mathrm{M}$ and $\mathrm{S}$ was significantly decreased in the inhibitor-treated group, compared with the NC group $(51.06 \pm 0.65 \%$ vs. $63.43 \pm 1.81 \%$; $\mathrm{P}<0.001)$. Furthermore, transfection with the miR-93-5p mimic significantly decreased the proportion of cells in $\mathrm{G}_{1}$ phase, compared with the NC group $(25.63 \pm 0.39 \%$ vs. $36.57 \pm 1.81 \%$; $\mathrm{P}<0.001)$. By contrast, the proportion of cells in the $\mathrm{G}_{2} / \mathrm{M}$ and $\mathrm{S}$ phase significantly increased, compared with the NC $(74.37 \pm 0.39 \%$ vs. $63.43 \pm 1.81 \%$; $\mathrm{P}<0.001)$. The results of the present study suggest that repression of miR-93-5p induces $G_{1}$ arrest, and inhibits cell proliferation and $\mathrm{G}_{1} / \mathrm{S}$ transition.

\section{Discussion}

MDR involves simultaneous resistance to multiple anti-cancer drugs and is, therefore, a frequent cause of chemotherapy failure, particularly in CRC $(7,45)$. Increasing evidence has revealed that aberrant miR expression contributes to the development of MDR in CRC (46). Valeri et al (47) reported that CRC cells with upregulated miR-21 expression exhibited significantly reduced sensitivity to therapeutics. In addition, Zhang et al (48) demonstrated that miR-153 overexpression led to oxaliplatin and cisplatin resistance in CRC. Furthermore, $\mathrm{Xu}$ et al (27) observed that miR-1915 was downregulated in drug-resistant HCT-116 and L-OHP cell lines, and that the upregulation of miR-1915 sensitized cells to anticancer drugs by reducing B-cell lymphoma-2 protein expression. However, the underlying mechanisms of drug resistance in CRC remain 
unclear. Additionally, a previous study indicated that miR-93 is dysregulated in human colon cancer and correlates with treatment resistance (33). In the present study, the role of miR-93-5p was further examined and observed to modulate MDR in human CRC cells by downregulating CDKN1A mRNA and protein expression.

Recently, miR mimic technology has proven to be a powerful tool in the study of specific miR functions, due to its stability and lack of off-target effects (49). In the present study, a synthetic miR mimic and inhibitor were used to investigate the role of miR-93-5p in chemoresistance in CRC. The results indicated that the expression of miR-93-5p was significantly increased in the drug-resistant HCT-8/VCR cell line, compared with the parental HCT- 8 cell line, and that this was accompanied by significantly increased MDR1 expression. Further investigation demonstrated that transfection of HCT-8/VCR cells with an miR-93-5p inhibitor significantly downregulated MDR1 expression, increased Rh-123 fluorescence intensity, enhanced sensitivity to VCR and induced $\mathrm{G}_{1}$ cell cycle arrest, compared with the miR-93-5p mimic and NC-transfected cells. Conversely, transfection of HCT-8 cells with an miR-93-5p mimic reduced sensitivity to VCR compared with the NC-transfected cells. The results of the present study suggest that the role of miR-93-5p in MDR is indirectly associated with modulation of MDR1 expression and cell cycle control.

At present, the most commonly studied underlying mechanism of MDR is the overexpression of efflux transporters, particularly MDR1 (13). MDR1 is a member of the ATP binding cassette transporter superfamily, which may reduce the accumulation of intracellular chemotherapeutics in tumor cells through the efflux of anti-cancer drugs (13). A number of miRs have been demonstrated to participate in the modulation of drug resistance by regulating the expression of MDR1, including miR-27a, miR-451, miR-298, miR-9 and miR-122 (50-53). In addition to MDR1 overexpression, regulation of the cell cycle in tumors has been indicated to be involved in the development of MDR (54). Huang et al (55) demonstrated that cell cycle regulation has an important role in chemoresistance in human ovarian cancer. The present study investigated the role of MDR1 and miR-93-5p-mediated cell cycle modulation in CRC chemoresistance.

In order to further elucidate the underlying mechanisms of MDR, factors involved in the direct regulation of MDR1 and miR-93-5p-mediated cell cycle progression were examined. Using PicTar, TargetScan and miRanda, CDKN1A was identified as a potential target of miR-93-5p. CDKN1A is a cyclin-dependent kinase inhibitor that belongs to the Cip/Kip family of cyclin kinase inhibitors and negatively modulates cell cycle progression (41). CDKN1A inhibits the activity of cyclin/cyclin-dependent kinase complexes, thus regulating $\mathrm{G}_{1} / \mathrm{S}$ cell cycle progression (42). CDKN1A causes $\mathrm{G}_{1}$ cell cycle arrest when overexpressed in cells (56). Furthermore, CDKN1A has been demonstrated to contribute to the chemotherapeutic response of cancer cells. Ding et al (57) observed that overexpression of CDKN1A sensitized human osteosarcoma cells to cisplatin. Qin et al (58) reported that upregulated expression of CDKN1A significantly increased the chemosensitivity of hepatoma cells to cisplatin. Abukhdeir et al (59) concluded that loss of CDKN1A function was associated with poor treatment response to tamoxifen in human breast cancer cells. In addition, Ziller et al (60) demonstrated that CDKN1 A was involved in drug resistance in ovarian carcinoma cells.

The present study aimed to validate the modulation of CDKN1A by miR-93-5p. Significantly elevated CDKN1A mRNA and protein expression was observed in miR-93-5p inhibitor-transfected HCT-8/VCR cells, compared with NC-transfected cells. Concurrently, transfection of HCT-8/VCR cells with an miR-93-5p inhibitor induced $\mathrm{G}_{1}$ cell cycle arrest and increased sensitivity to VCR. The results of the present study suggest that CDKN1A is a direct target of miR-93-5p and that repression of miR-93-5p restores CDKN1A function. Furthermore, Wu et al (37) demonstrated that aberrant expression of miR-93 was negatively associated with CDKN1A protein expression. In addition, luciferase reporter assays have identified CDKN1A to be a direct target of miR-93 $(37,61,62)$. The results of the present study indicate that miR-93-5p participates in the development of MDR by downregulating the expression of CDKN1A, subsequently modulating MDR1 expression and cell cycle progression.

In conclusion, the results of the present study demonstrate that miR-93-5p is upregulated in drug-resistant CRC cells and that downregulation of miR-93-5p results in increased chemotherapeutic sensitivity. This suggests that miR-93-5p modulates MDR in CRC. Inhibition of miR-93-5p was found to downregulate MDR1 expression, increase intracellular chemotherapeutic drug concentration and increase the proportion of cells in $\mathrm{G}_{1}$, through upregulating CDKN1A mRNA and protein expression. Therefore, the present study indicates that miR-93-5p is a novel therapeutic target for the treatment of CRC with MDR.

\section{Acknowledgements}

Thepresentstudy was supportedby TheNational NaturalScience Foundation of China (grant nos. 81260316 and 81260335). Furthermore, the authors thank Professor Lian-Ying Ge (Affiliated Tumor Hospital of Guangxi Medical University, Nanning, China) for her advice, technical assistance and critical reading of this manuscript.

\section{References}

1. Siegel RL, Miller KD and Jemal A: Cancer statistics, 2015. CA Cancer J Clin 65: 5-29, 2015.

2. Sung JJ, Lau JY, Goh KL and Leung WK; Asia Pacific Working Group on Colorectal Cancer: Increasing incidence of colorectal cancer in Asia: Implications for screening. Lancet Oncol 6: 871-876, 2005.

3. Siegel R, Desantis $C$ and Jemal A: Colorectal cancer statistics, 2014. CA Cancer J Clin 64: 104-117, 2014.

4. Li M and Gu J: Changing patterns of colorectal cancer in China over a period of 20 years. World J Gastroenterol 11: 4685-4688, 2005.

5. Henaine AM, Chahine G, Salameh P, Elias E, Massoud M, Hartmann D, Aulagner G and Armoiry X: MANAGEMENT OF METASTATIC COLORECTAL CANCER: Current Treatments and New Therapies. J Med Liban 63: 218-227, 2015.

6. Kozovska Z, Gabrisova V and Kucerova L: Colon cancer: Cancer stem cells markers, drug resistance and treatment. Biomed Pharmacother 68: 911-916, 2014.

7. Temraz S, Mukherji D, Alameddine R and Shamseddine A: Methods of overcoming treatment resistance in colorectal cancer. Crit Rev Oncol Hematol 89: 217-230, 2014.

8. Kelland L: The resurgence of platinum-based cancer chemotherapy. Nat Rev Cancer 7: 573-584, 2007. 
9. Dai Z, Huang Y and Sadee W: Growth factor signaling and resistance to cancer chemotherapy. Curr Top Med Chem 4: 1347-1356, 2004.

10. Schickel R, Boyerinas B, Park SM and Peter ME: MicroRNAs: Key players in the immune system, differentiation, tumorigenesis and cell death. Oncogene 27: 5959-5974, 2008.

11. Zhu W, Zhu D, Lu S, Wang T, Wang J, Jiang B, Shu Y and Liu P: miR-497 modulates multidrug resistance of human cancer cell lines by targeting BCL2. Med Oncol 29: 384-391, 2012.

12. Yang T, Zheng ZM, Li XN, Li ZF, Wang Y, Geng YF, Bai L and Zhang XB: MiR-223 modulates multidrug resistance via downregulation of ABCB1 in hepatocellular carcinoma cells. Exp Bio Med (Maywood) 238: 1024-1032, 2013.

13. Xia $\mathrm{H}$ and Hui KM: Mechanism of cancer drug resistance and the involvement of noncoding RNAs. Curr Med Chem 21: 3029-3041, 2014

14. Zong C, Wang J and Shi TM: MicroRNA 130b enhances drug resistance in human ovarian cancer cells. Tumour Biol 35: 12151-12156, 2014

15. Bartel DP: MicroRNAs: Genomics, biogenesis, mechanism, and function. Cell 116: 281-297, 2004.

16. Barbarotto E, Schmittgen TD and Calin GA: MicroRNAs and cancer: Profile, profile, profile. Int J Cancer 122: 969-977, 2008.

17. Valencia-Sanchez MA, Liu J, Hannon GJ and Parker R: Control of translation and mRNA degradation by miRNAs and siRNAs. Genes Dev 20: 515-524, 2006.

18. Filipowicz W, Bhattacharyya SN and Sonenberg N: Mechanisms of post-transcriptional regulation by microRNAs: Are the answers in sight? Nat Rev Genet 9: 102-114, 2008.

19. Hwang HW and Mendell JT: MicroRNAs in cell proliferation, cell death, and tumorigenesis. Br J Cancer 94: 776-780, 2006.

20. Osada $\mathrm{H}$ and Takahashi T: MicroRNAs in biological processes and carcinogenesis. Carcinogenesis 28: 2-12, 2007.

21. Chen CZ: MicroRNAs as oncogenes and tumor suppressors. $\mathrm{N}$ Engl J Med 353: 1768-1771, 2005.

22. Cho WC: OncomiRs: The discovery and progress of microRNAs in cancers. Mol Cancer 6: 60, 2007.

23. Xue J, Niu J, Wu J and Wu ZH: MicroRNAs in cancer therapeutic response: Friend and foe. World J Clin Oncol 5: 730-743, 2014.

24. Fang L, Li H, Wang L, Hu J, Jin T, Wang J and Yang BB: MicroRNA-17-5p promotes chemotherapeutic drug resistance and tumour metastasis of colorectal cancer by repressing PTEN expression. Oncotarget 5: 2974-2987, 2014.

25. Shang Y, Zhang Z, Liu Z, Feng B, Ren G, Li K, Zhou L, Sun Y, Li M,Zhou J, et al: miR-508-5p regulates multidrug resistance of gastric cancer by targeting ABCB1 and ZNRD1. Oncogene 33 3267-3276, 2014

26. Rasmussen MH, Jensen NF, Tarpgaard LS, Qvortrup C, Rømer MU, Stenvang J, Hansen TP, Christensen LL, Lindebjerg J, Hansen F, et al: High expression of microRNA-625-3p is associated with poor response to first-line oxaliplatin based treatment of metastatic colorectal cancer. Mol Oncol 7: 637-646, 2013.

27. Xu K, Liang X, Cui D, Wu Y, Shi W and Liu J: miR-1915 inhibits $\mathrm{Bcl}-2$ to modulate multidrug resistance by increasing drug-sensitivity in human colorectal carcinoma cells. Mol Carcinog 52: 70-78, 2013.

28. Sui H, Cai GX, Pan SF, Deng WL, Wang YW, Chen ZS, Cai SJ, Zhu HR and Li Q: miR200c attenuates P-gp-mediated MDR and metastasis by targeting JNK2/c-Jun signaling pathway in colorectal cancer. Mol Cancer Ther 13: 3137-3151, 2014

29. Liao H, Bai Y, Qiu S, Zheng L, Huang L, Liu T, Wang X, Liu Y, Xu N, Yan X and Guo H: MiR-203 downregulation is responsible for chemoresistance in human glioblastoma by promoting epithelial-mesenchymal transition via SNAI2. Oncotarget 6: 8914-8928, 2015

30. Wang Z, Liu M, Zhu H, Zhang W, He S, Hu C, Quan L, Bai J and Xu N: Suppression of p21 by c-Myc through members of miR-17 family at the post-transcriptional level. Int J Oncol 37: $1315-1321,2010$.

31. Nam EJ, Yoon H, Kim SW, Kim H, Kim YT, Kim JH, Kim JW and Kim S: MicroRNA expression profiles in serous ovarian carcinoma. Clin Cancer Res 14: 2690-2695, 2008.

32. Kim YK, Yu J, Han TS, Park SY, Namkoong B, Kim DH, Hur K, Yoo MW, Lee HJ, Yang HK and Kim VN: Functional links between clustered microRNAs: Suppression of cell-cycle inhibitors by microRNA clusters in gastric cancer. Nucleic Acids Res 37: 1672-1681, 2009.

33. Zhou J, Zhou Y, Yin B, Hao W, Zhao L, Ju W and Bai C: 5-Fluorouracil and oxaliplatin modify the expression profiles of microRNAs in human colon cancer cells in vitro. Oncol Rep 23: 121-128, 2010
34. Yu XF, Zou J, Bao ZJ and Dong J: miR-93 suppresses proliferation and colony formation of human colon cancer stem cells. World J Gastroenterol 17: 4711-4717, 2011.

35. Liu S, Patel SH, Ginestier C, Ibarra I, Martin-Trevino R, Bai S, McDermott SP, Shang L, Ke J, Ou SJ, et al: MicroRNA93 regulates proliferation and differentiation of normal and malignant breast stem cells. PLoS Genet 8: e1002751, 2012.

36. Fu X, Tian J, Zhang L, Chen Y and Hao Q: Involvement of microRNA-93, a new regulator of PTEN/Akt signaling pathway, in regulation of chemotherapeutic drug cisplatin chemosensitivity in ovarian cancer cells. FEBS Lett 586: 1279-1286, 2012.

37. Wu ZB, Li WQ, Lin SJ, Wang CD, Cai L, Lu JL, Chen YX, Su ZP, Shang HB, Yang WL, et al: MicroRNA expression profile of bromocriptine-resistant prolactinomas. Mol Cell Endocrinol 395: 10-18, 2014.

38. Livak KJ and Schmittgen TD: Analysis of relative gene expression data using real-time quantitative PCR and the 2(-Delta Delta C (T)) Method. Methods 25: 402-408, 2001.

39. Zhu H, Cai C and Chen J: Suppression of P-glycoprotein gene expression in Hs578T/Dox by the overexpression of caveolin-1. FEBS Lett 576: 369-374, 2004.

40. Zhu W, Xu H, Zhu D, Zhi H, Wang T, Wang J, Jiang B, Shu Y and Liu P: miR-200bc/429 cluster modulates multidrug resistance of human cancer cell lines by targeting BCL2 and XIAP. Cancer Chemother Pharmacol 69: 723-731, 2012.

41. Harper JW, Adami GR, Wei N, Keyomarsi K and Elledge SJ: The p21 Cdk-interacting protein Cip1 is a potent inhibitor of G1 cyclin-dependent kinases. Cell 75: 805-816, 1993.

42. Xiong Y, Hannon GJ, Zhang H, Casso D, Kobayashi R and Beach D: p21 is a universal inhibitor of cyclin kinases. Nature 366: 701-704, 1993.

43. Tang Q, Zou Z, Zou C, Zhang Q, Huang R, Guan X, Li Q, Han Z, Wang D, Wei H, et al: MicroRNA-93 suppress colorectal cancer development via Wnt/ $\beta$-catenin pathway downregulating. Tumour Biol 36: 1701-1710, 2015.

44. Chai H, Liu M, Tian R, Li X and Tang H: miR-20a targets BNIP2 and contributes chemotherapeutic resistance in colorectal adenocarcinoma SW480 and SW620 cell lines. Acta Biochim Biophys Sin (Shanghai) 43: 217-225, 2011

45. Baguley BC: Multiple drug resistance mechanisms in cancer. Mol Biotechnol 46: 308-316, 2010.

46. Yu X, Li Z, Yu J, Chan MT and Wu WK: MicroRNAs predict and modulate responses to chemotherapy in colorectal cancer. Cell Prolif 48: 503-510, 2015

47. Valeri N, Gasparini P, Braconi C, Paone A, Lovat F, Fabbri M, Sumani KM, Alder H, Amadori D, Patel T, et al: MicroRNA-21 induces resistance to 5 -fluorouracil by down-regulating human DNA MutS homolog 2 (hMSH2). Proc Natl Acad Sci USA 107: 21098-21103, 2010

48. Zhang L, Pickard K, Jenei V, Bullock MD, Bruce A, Mitter R, Kelly G, Paraskeva C, Strefford J, Primrose J, et al: miR-153 supports colorectal cancer progression via pleiotropic effects that enhance invasion and chemotherapeutic resistance. Cancer Res 73: 6435-6447, 2013.

49. Wang Z: The guideline of the design and validation of miRNA mimics. Methods Mol Biol 676: 211-223, 2011.

50. Zhu H, Wu H, Liu X, Evans BR, Medina DJ, Liu CG and Yang JM: Role of MicroRNA miR-27a and miR-451 in the regulation of MDR1/P-glycoprotein expression in human cancer cells. Biochem Pharmacol 76: 582-588, 2008

51. Xu Y, Xia F, Ma L, Shan J, Shen J, Yang Z, Liu J, Cui Y, Bian X, Bie P and Qian C: MicroRNA-122 sensitizes HCC cancer cells to adriamycin and vincristine through modulating expression of MDR and inducing cell cycle arrest. Cancer Lett 310: 160-169, 2011.

52. Bao L, Hazari S, Mehra S, Kaushal D, Moroz K and Dash S: Increased expression of P-glycoprotein and doxorubicin chemoresistance of metastatic breast cancer is regulated by miR-298. Am J Pathol 180: 2490-2503, 2012

53. Munoz JL, Bliss SA, Greco SJ, Ramkissoon SH, Ligon KL and Rameshwar P: Delivery of functional anti-miR-9 by mesenchymal stem cell-derived exosomes to glioblastoma multiforme cells conferred chemosensitivity. Mol Ther Nucleic Acids 2: e126, 2013.

54. Tomida A and Tsuruo T: Drug resistance mediated by cellular stress response to the microenvironment of solid tumors. Anticancer Drug Des 14: 169-177, 1999.

55. Huang L, Ao Q, Zhang Q, Yang X, Xing H, Li F, Chen G, Zhou J, Wang S, Xu G, et al: Hypoxia induced paclitaxel resistance in human ovarian cancers via hypoxia-inducible factor 1alpha. J Cancer Res Clin Oncol 136: 447-456, 2010. 
56. Warfel NA and El-Deiry WS: p21WAF1 and tumourigenesis: 20 years after. Curr Opin Oncol 25: 52-58, 2013.

57. Ding Y, Wang Y, Chen J, Hu Y, Cao Z, Ren P and Zhang Y: p21 overexpression sensitizes osteosarcoma U2OS cells to cisplatin via evoking caspase-3 and $\mathrm{Bax} / \mathrm{Bcl}-2$ cascade. Tumour Biol 35: 3119-3123, 2014.

58. Qin LF and Ng IO: Exogenous expression of p21 (WAF1/ CIP1) exerts cell growth inhibition and enhances sensitivity to cisplatin in hepatoma cells. Cancer Lett 172: 7-15, 2001 .

59. Abukhdeir AM, Vitolo MI, Argani P, De Marzo AM, Karakas B, Konishi H, Gustin JP, Lauring J, Garay JP, Pendleton C, et al: Tamoxifen-stimulated growth of breast cancer due to p21 loss. Proc Natl Acad Sci USA 105: 288-293, 2008.
60. Ziller C, Lincet H, Muller CD, Staedel C, Behr JP and Poulain L: The cyclin-dependent kinase inhibitor p21 (cip1/waf1) enhances the cytotoxicity of ganciclovir in HSV-tk transfected ovarian carcinoma cells. Cancer Lett 212: 43-52, 2004.

61. Ivanovska I, Ball AS, Diaz RL, Magnus JF, Kibukawa M, Schelter JM, Kobayashi SV, Lim L, Burchard J, Jackson AL, et al: MicroRNAs in the miR-106b family regulate p21/CDKN1A and promote cell cycle progression. Mol Cell Biol 28: 2167-2174, 2008

62. LiZ, Yang CS, Nakashima K and Rana TM: Small RNA-mediated regulation of iPS cell generation. EMBO J 30: 823-834, 2011 